\title{
Peltopyy ja monimuotoisuuden ohjauskeinot
}

Antti Miettinen ja Anni Huhtala

MTT Taloustutkimus, Luutnantintie 13, 00410 Helsinki

sähköposti: etunimi.sukunimi@mtt.fi

\section{Tiivistelmä}

Tutkimuksessa tarkastellaan viljelykasvivalinnan ja tuotantotavan (tavanomainen tai luonnonmukainen) sekä torjunta-aineiden käytön ja metsästäjien metsästyspäätösten vaikutuksia yhteiskunnalliseen hyvinvointiin ja luonnon monimuotoisuuteen. Monimuotoisuuden indikaattorina käytetään peltopyykantaa. Peltopyy (Perdix perdix) soveltuu hyvin maatalousympäristön ja erityisesti peltoluonnon monimuotoisuutta mittaavaksi indikaattorilajiksi, koska peltopyyt pesivät ja ruokailevat pelloilla.

Luonnonmukaisesti viljelty ruis on tutkimuksessa esimerkkinä ympäristöhyötyjä tuottavasta viljelykasvista. Syysrukiin oras tarjoaa talvista viherravintoa muun muassa peltopyille, eikä luomuviljelyssä käytetä lainkaan kemiallisia torjunta-aineita. Tavanomaisessa tuotannossa käytettävät kemialliset kasvinsuojeluaineet parantavat viljelykasvien (tutkimuksessa kevätvehnän) tuottavuutta, mutta ne lisäävät myös peltopyiden poikaskuolleisuutta, koska torjunta-aineet vähentävät poikasten tarvitsemaa hyönteisravintoa. Ympäristöön kohdistuvien haittojen lisäksi torjunta-aineet aiheuttavat myös terveysriskejä ihmisille.

Peltoviljelyn tuottamat hyödyt ja haitat sekä peltopyykannan tuottamat hyödyt tulee sisäistää taloudellisilla ohjauskeinoilla. Ellei niin tehdä, viljelijöillä ja metsästäjillä ei ole riittäviä kannustimia toimia monimuotoisuuden suojelemiseksi vaan liian pieni osa peltopinta-alasta käytetään ympäristöhyötyjä tuottavan luomurukiin tuotantoon. Vastaavasti kemiallisia torjunta-aineita käytetään liian paljon, ja peltopyykanta jää myös liiallisen metsästyksen takia pieneksi.

Tutkimuksessa johdetaan yhteiskunnallisesti optimaaliset, maatalousluonnon monimuotoisuutta edistävät ohjauskeinot, joita voidaan hyödyntää maatalouden ympäristöpolitiikassa ja riistanhoidossa. Luomurukiinviljelyn tuottamat ympäristöhyödyt saadaan sisäistettyä maksamalla luonnonmukaisesti tuotetulle rukiille viljelyalaperusteista tukea. Torjunta-aineiden käytölle on asetettava vero. Veron avulla saadaan sisäistettyä sekä torjunta-aineiden ihmisille aiheuttamat terveysriskit että myös torjunta-aineiden aiheuttamat peltopyykannan kasvutappiot. Luomurukiinviljelyn hehtaarituen ja torjunta-aineveron lisäksi tarvitaan myös pyyntilupamaksu peltopyyn metsästystä ohjaamaan.

Tuen, veron ja pyyntilupamaksun suuruudet riippuvat keskeisesti siitä, kuinka arvokkaana monimuotoista peltokasvituotantoa ja sen indikaattorina olevaa peltopyytä pidetään. Ohjauskeinojen mitoittamisessa hyödynnetään aiempia kotimaisia tutkimuksia.

Asiasanat: luonnon monimuotoisuus, optimiohjaus, peltopyy, ruis, torjunta-aineet 


\section{Johdanto}

Eurooppalainen maataloustuotanto on viime vuosikymmeninä tehostunut ja erikoistunut. Tehostumisella ja erikoistumisella on ollut sekä myönteisiä että kielteisiä vaikutuksia. Vaikutukset peltoluonnon monimuotoisuuteen ovat olleet pääasiassa kielteisiä, koska viljelykasvivalikoima on kaventunut, viljelykierrot ovat yksipuolistuneet ja kasvinsuojeluaineiden käyttö on ollut runsasta. Vaikutukset ovat ilmenneet muun muassa maatalousympäristön lintujen laji- ja yksilömäärien vähenemisinä. Erityisesti peltopyiden (Perdix perdix) lukumäärä on vähentynyt huomattavasti. Väheneminen on huolestuttavaa, koska peltopyytä pidetään erittäin hyvänä peltoluonnon monimuotoisuutta mittaavana indikaattorina. (Potts, 1986; Hagemeijer ja Blair, 1997; Potts, 1997; Sotherton, 1998; Chamberlain ja Fuller, 2000; De Leo ym., 2004).

Suomessa peltopyy on luokiteltu silmälläpidettäväksi lajiksi (Rassi ym., 2001). Sitä tavataan lähinnä Länsi- ja Etelä-Suomessa. Pesiviä peltopyypareja on nykyään vain 4000 kappaletta. 1950-luvulla pesiviä pareja oli 15000 (Väisänen ym., 1998). Vuosittainen peltopyysaalis on viimeisen kahdenkymmenen vuoden ajan ollut noin $1000 \mathrm{~kg}$ eli noin 2000 lintua (RKTL, 2004). 1950-luvulla peltopyysaalis oli kaksi kertaa suurempi. Suomalaisen peltopyykannan pienenemisen syitä ovat syysvilja-alan väheneminen ja torjunta-aineiden käytön lisääntyminen (Tiainen ja Pakkala, 1996).

Syysviljojen viljely on Suomessa vähentynyt, koska viljelijät saavat paremman ja varmemman tuoton kevätviljojen viljelystä. Tärkeimmän syysviljan eli rukiin viljelyala on viime vuosina ollut alle $3 \%$ vilja-alasta (TIKE, 2003). Vielä 1950-luvulla ruisala oli yli kolminkertainen nykyiseen verrattuna. Rukiin viljelyalan vähenemisestä ovat peltopyiden lisäksi kärsineet muutkin lajit, kuten fasaanit ja rusakot, joille syysrukiin oras tarjoaa viherravintoa talvella ja keväällä.

Talvisen viherravinnon lisäksi rukiinviljelyn ulkoisvaikutuksina syntyy myös muita ympäristöhyötyjä. Yli 20 \% Suomen ruisalasta on luonnonmukaisesti viljeltyä (KTTK, 2003). Luonnonmukaisessa tuotannossa ei käytetä lainkaan kemiallisia torjunta-aineita ja myös tavanomaisessa rukiinviljelyssä rikkakasvihävitteitä tarvitaan vähemmän kuin kevätviljapelloilla (Raatikainen ym., 1978). Koska rikkakasvien torjunta-aineet vähentävät myös hyönteisten lukumäärää, rikkakasvihävitteiden vähäinen käyttö hyödyttää muun muassa peltopyiden poikasia, jotka muutamana ensimmäisenä elinviikkonaan tarvitsevat kehittyäkseen hyönteisravintoa (Potts, 1986).

Tutkimuksen tavoitteena on löytää (first-best) ohjauskeinot ulkoisvaikutusten sisäistämiseksi ja peltopyykannan ylläpitämiseksi yhteiskunnallisesti optimaalisella tasolla. Ellei korjaaviin toimenpiteisiin ryhdytä, vähenevät peltopyykanta ja viljeltyjen alueiden monimuotoisuus tulevaisuudessa entisestään.

Maatalouden monivaikutteisuutta käsittelevän kirjallisuuden (mm. Peterson ym., 2002; Lankoski ja Ollikainen, 2003; Dobbs ja Pretty, 2004) lisäksi työn keskeisenä lähteenä on Hammackin ja Brownin (1974) pohjoisamerikkalainen vesilintututkimus, jossa lampien ja kosteikkojen kuivattaminen lisää maatalousmaan ja maataloudesta saatavien tulojen määrää, mutta vähentää vesilintujen pesimäalueiden ja vesilinnuista saatavien hyötyjen määrää.

\section{Aineisto ja menetelmät}

Peltoluonnon monimuotoisuutta ja peltopyyn suojelua tarkastellaan dynaamisen optimiohjausmallin avulla. Mallin idea on seuraavanlainen. Viljelijät viljelevät joko luomuruista tai tavanomaisesti tuotettua kevätvehnää. Luomurukiin viljelyalan lisääminen tuottaa myönteisiä ulkoisvaikutuksia ja lisää peltopyykannan kasvua, koska luonnonmukaisessa tuotannossa ei käytetä kemiallisia torjunta-aineita ja linnut saavat rukiin oraasta viherravintoa talvella. Kevätvehnästä viljelijä saa paremman tuoton kuin rukiista, mutta kevätvehnän kasvinsuojelussa käytetään kemiallisia torjunta-aineita, joiden käyttö lisää peltopyiden poikaskuolleisuutta ja aiheuttaa myös suoraan haittaa ihmisille. Torjunta-aineiden haittoja ihmisille ovat muun muassa myrkytykset ja torjunta-ainejäämien terveysriskit. Metsästäjät pyrkivät metsästystä säätelemällä maksimoimaan peltopyysaaliin arvon. Metsästysoikeus kuuluu maanomistajille, mutta mallissa oletetaan, että maanomistajat vuokraavat metsästysoikeutensa nimellistä korvausta vastaan metsästysseuroille, jotka huolehtivat myös riistanhoidosta. Riistasaaliin lisäksi peltopyykanta tuottaa yhteiskunnalle myös muita kuin metsästyksen kautta saatavia hyötyjä, sillä peltopyyllä on myös olemassaoloarvo.

Tutkimuksessa osoitetaan, että ilman yhteiskunnan väliintuloa luonnonmukaisesti viljelty ruisala jää liian pieneksi, torjunta-aineita käytetään liian paljon ja peltopyitä metsästetään liikaa. Tämä johtuu siitä, että viljelijöillä ja metsästäjillä ei ole taloudellisia kannustimia huomioida päätöstensä monimuotoisuusvaikutuksia. Luonnon monimuotoisuus on julkishyödyke, jota kaikki käyttävät riippumatta sen maksajasta. Näin ollen esimerkiksi luomurukiinviljelijöiden tuottamat monimuotoisuushyödyt jakaantuvat suurelle 
joukolle ihmisiä, vaikka monimuotoisuuden tuottamisen kustannuksista (luomurukiinviljelyn vaihtoehtoiskustannus) vastaavat pelkästään luomurukiinviljelijät.

Ulkoisvaikutusten sisäistämiseen tarvitaan taloudellisia ohjauskeinoja, jotka ovat rukiinviljelyn hehtaarituki, torjunta-ainevero sekä peltopyyn metsästyksestä perittävä pyyntilupamaksu. Ohjauskeinojen mitoittamisessa hyödynnetään tilastotietoja sekä Ovaskaisen ym. (1992) ja Siikamäen (1997) tutkimustuloksia.

\section{Tulokset ja tulosten tarkastelu}

Rukiinviljelyn hehtaarituen, torjunta-aineveron ja peltopyyn pyyntilupamaksun suuruudet riippuvat keskeisesti siitä, kuinka arvokkaana peltopyytä pidetään. Riista- ja kalatalouden tutkimuslaitoksen tilastojen mukaan peltopyystä saatavan lihan arvo on noin 5 euroa (RKTL, 2004). Ovaskaisen ym. (1992) tutkimustulosten mukaan metsäkanalintujen lihan arvo oli vain 11-12 prosenttia näiden lintujen metsästyksen kokonaisarvosta. Mikäli tämä tulos pätee myös peltopyylle, on metsästyssaaliiksi saadun peltopyyn arvo (varjohinta) noin 45 euroa.

Torjunta-aineiden käytön lisäämisen suoraksi yhteiskunnalliseksi rajahaitaksi oletetaan 114 euroa per hehtaari. Arvio perustuu Siikamäen (1997) tutkimukseen, jonka mukaan suomalaiset kuluttajat ovat halukkaita maksamaan vuosittain noin 250 miljoonaa euroa, mikäli torjunta-aineiden käyttö maataloudessa lopetetaan kokonaan. Koska Suomen peltopinta-ala on noin 2,2 miljoonaa hehtaaria, saadaan kokonaismaksuhalukkuudeksi 114 euroa per hehtaari.

Ohjauskeinojen suuruuden määrittämiseksi tarvitaan lisäksi arviot, miten paljon torjunta-aineiden käytön vähentäminen ja luomuruisalan lisääminen lisäävät peltopyiden poikastuotantoa. Arviot on laskettu sovittamalla käytössä oleva peltopyyaineisto pitkän aikavälin tasapainoyhtälöön ja tutkimalla kuinka poikastuotanto muuttuu mikäli torjunta-aineiden käytössä tai luomuruisalassa tapahtuu muutoksia Laskelmien perusteella torjunta-aineiden käytön lopettaminen lisää poikastuotantoa 0,10 peltopyytä per hehtaari. Vastaavasti luomuruishehtaari lisää poikastuotantoa 0,39 peltopyytä per hehtaari.

Tuen, veron ja pyyntilupamaksun suuruudet on esitetty taulukossa 1 . Alustavien tulosten perusteella luomurukiille maksettavan tuen suuruus on noin 18 euroa hehtaaria kohti. Torjunta-aineiden käytöstä perittävä vero on melko suuri, 119 euroa hehtaaria kohti laskettuna. Veron avulla saadaan sisäistettyä sekä torjunta-aineiden ihmisille aiheuttamat terveysriskit että myös torjunta-aineiden aiheuttamat peltopyykannan kasvutappiot. Peltopyyn metsästämisestä perittävä pyyntilupamaksu on puolestaan 45 euroa per lintu.

Taulukko 1. Monimuotoisuuden ohjauskeinot

\begin{tabular}{lr}
\hline Rukiinviljelyn hehtaarituki & $45 \times 0,39=18$ euroa/hehtaari \\
Torjunta-ainevero & $114+(45 \times 0,10)=119$ euroa/hehtaari \\
Peltopyyn pyyntilupamaksu & 45 euroa/peltopyy \\
\hline
\end{tabular}

\section{Johtopäätökset}

Tutkimus paljastaa omalta osaltaan miksi luonnon monimuotoisuus on vähentynyt maatalousympäristössä. Maataloustuotannon ulkoisvaikutuksista ja luonnon monimuotoisuuden julkishyödykeominaisuudesta johtuen markkinat epäonnistuvat maatalousympäristön monimuotoisuuden turvaamisessa. Ilman yhteiskunnan väliintuloa monimuotoisuushyötyjä tuotetaan liian vähän, koska hyötyjen tuottajilla ei ole taloudellisia kannustimia tuottaa niitä. Sen sijaan haitallisia ulkoisvaikutuksia tuotetaan liikaa, koska haitallisten ulkoisvaikutusten tuottaja ei joudu maksamaan niiden tuottamisesta aiheutuvia yhteiskunnallisia kustannuksia.

Tarkastellussa mallissa oli kolme ulkoisvaikutusta, joiden sisäistämiseen tarvittiin kolme taloudellista ohjauskeinoa. Ohjauskeinot olivat luomurukiille maksettava viljelyalaperusteinen tuki, torjunta-ainevero sekä peltopyyn pyyntilupamaksu.

Suomessa on tällä hetkellä käytössä ainoastaan maatalouden ympäristötuen erityistukisopimuksiin kuuluva luonnonmukaisen tuotannon tuki, jonka suuruus on vuodessa 102,59 euroa per hehtaari kahden vuoden siirtymäkauden jälkeen (jonka aikana vuotuinen tuki on 147,16 euroa per hehtaari). Torjuntaaineiden käyttöä ei veroteta, ja pyyntilupamaksu peritään vain hirvieläimistä.

Tutkimuksessa esiteltiin yksinkertainen kehikko, joka selventää kuinka monimuotoisuuteen liittyvät arvot voidaan sisällyttää viljelijöiden ja metsästäjien päätöksentekoon. Koska luomurukiinviljelyn vaihto- 
ehtoiskustannukset ovat melko suuret, yli 200 euroa per hehtaari, ei luomurukiinviljelyn tukeminen varmastikaan ole kustannustehokkain tapa suojella pelkkää peltopyytä. Onkin tärkeää muistaa, että monimuotoisesta peltokasvituotannosta hyötyvät myös monet muut lajit kuin tässä tutkimuksessa monimuotoisuuden indikaattorina ollut peltopyy.

Lisäksi on syytä huomata, että ohjauskeinojen suuruus vaihtelee ajassa riippuen erityisesti monimuotoisuuden arvostuksesta. Luomuviljelyä tuetaan ja torjunta-aineiden käyttöä verotetaan aiempaa enemmän, jos monimuotoista maatalousympäristöä arvostetaan tulevaisuudessa entistä enemmän. Monimuotoisuuden arvostukset heijastuvat myös riistanhoitoon pyyntilupamaksun korotuksina.

\section{Kiitokset}

Kirjoittajat kiittävät peltopyytä koskevista tiedoista dosentti Juha Tiaista Riista- ja kalatalouden tutkimuslaitoksesta.

\section{Kirjallisuus}

Chamberlain, D.E. \& Fuller, R.J. 2000. Local extinctions and changes in species richness of lowland farm birds in England and Wales in relation to recent changes in agricultural land-use. Agriculture, Ecosystems and Environment 78: 1-17.

De Leo, G.A., Focardi, S., Gatto, M. \& Cattadori, I.M. 2004. The decline of the grey partridge in Europe: comparing demographies in traditional and modern agricultural landscapes. Ecological Modelling 177: 313-335.

Dobbs, T. \& Pretty, J.N. 2004. Agri-Environmental Stewardship Schemes and "Multifunctionality". Review of Agricultural Economics 26: 220-237.

Hagemeijer, W.J.M. \& Blair, M.J. (toim.) 1997. The EBCC Atlas of European Breeding Birds: Their Distribution and Abundance. Published for the European Bird Census Council. London: Poyser.

Hammack, J. \& Brown, G.M., Jr. 1974. Waterfowl and Wetlands: Toward Bioeconomic Analysis. Baltimore: Johns Hopkins University Press.

KTTK (Kasvintuotannon tarkastuskeskus). 2003. Luonnonmukainen maatalous 2002 - Tilastoja. KTTK:n julkaisuja B2 Luomutuotanto 2/2003. Loimaa: Kasvintuotannon tarkastuskeskus.

Lankoski, J. \& Ollikainen, M. 2003. Agri-environmental externalities: a framework for designing targeted policies. European Review of Agricultural Economics 30: 51-75.

Ovaskainen, V., Savolainen H. \& Sievänen, T. 1992. The benefits of managing forests for grouse habitats: A contingent valuation experiment. Teoksessa Solberg, B. (toim.), Proceedings of the Biennial Meeting of the Scandinavian Society of Forest Economics, Gausdal, Norway, April 1991. Scandinavian Forest Economics 33: 263-274.

Peterson, J.M., Boisvert, R.N. \& de Gorter, H. 2002. Environmental policies for a multifunctional agricultural sector in open economies. European Review of Agricultural Economics 29: 423-443.

Potts, D. 1997. Cereal farming, pesticides and grey partridges. Teoksessa Pain, D.J. \& Pienkowski, M.W. (toim.), Farming and Birds in Europe: The Common Agricultural Policy and its Implications for Bird Conservation. London: Academic Press, 150-177.

Potts, G.R. 1986. The Partridge: Pesticides, Predation and Conservation. London: Collins.

Raatikainen, M., Raatikainen, T. \& Mukula, J. 1978. Weed species, frequencies and densities in winter cereals in Finland. Annales Agriculturae Fenniae 17: 115-142.

Rassi, P., Alanen, A., Kanerva, T. \& Mannerkoski, I. (toim.) 2001. Suomen lajien uhanalaisuus 2000. Uhanalaisten lajien II seurantaryhmä. Helsinki: ympäristöministeriö ja Suomen ympäristökeskus.

RKTL (Riista- ja kalatalouden tutkimuslaitos). 2004. Riistasaalis 2003. Helsinki: Riista- ja kalatalouden tutkimuslaitos.

Siikamäki, J. 1997. Torjunta-aineiden käytön vähentämisen arvo? Contingent valuation -tutkimus kuluttajien maksuhalukkuudesta. Maatalouden taloudellisen tutkimuslaitoksen tutkimuksia 217. Helsinki: Maatalouden taloudellinen tutkimuslaitos.

Sotherton, N.W. 1998. Land use changes and the decline of farmland wildlife: An appraisal of the set-aside approach. Biological Conservation 83: 259-268.

Tiainen, J. \& Pakkala, T. 1996. Peltopyy (Perdix perdix). Teoksessa Lindén, H., Hario, M. \& Wikman, M. (toim.) Riistan jäljille. Helsinki: Riista- ja kalatalouden tutkimuslaitos, 186-189.

TIKE (Maa- ja metsätalousministeriön tietopalvelukeskus). 2003. Maatilatilastollinen vuosikirja 2003. Helsinki: Maa- ja metsätalousministeriön tietopalvelukeskus.

Väisänen, R.A., Lammi, E. \& Koskimies, P. 1998. Muuttuva pesimälinnusto. Helsinki: Otava. 